\title{
Geschichte intellektuell
}

\author{
Theoriegeschichtliche Perspektiven \\ Hrsg. v. Friedrich Wilhelm Graf, Edith Hanke u. Barbara Picht
}

Geschichte intellektuell

Theoriegeschichtliche Perspektiven

Herausgegeben von

Friedrich Wilhelm Graf, Edith Hank

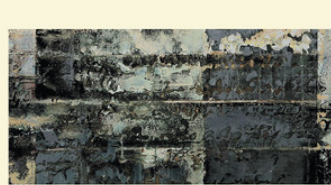

Mohr Siebeck

2015. VIII, 533 Seiten.

ISBN 978-3-16-154161-2

DOI 10.1628/978-3-16-154161-2

eBook PDF 79,00€

ISBN 978-3-16-153317-4

Festeinband $79,00 €$
Geschichte intellektuell, das heißt: Geschichte in ihrer Relevanz für unsere Gegenwart und das politische Handeln zu denken. 28 Autorinnen und Autoren aus den Geschichts-, Sozial- und Kulturwissenschaften denken über dieses Wechsel- und Spannungsverhältnis in diesem Band neu nach: über Grundfragen der Geschichtstheorie und ihren Standort als Wissenschaftlerinnen und Wissenschaftler heute. Sie porträtieren Geschichtsdenker und Geschichtsintellektuelle wie Jacob Burckhardt, Max Weber, Eric Hobsbawm und Stefan Czarnowski. Indem sie Geschichte interdisziplinär denken, befassen sie sich mit Begriffen und deren Transfer aus den Nachbardisziplinen und in andere Kulturen. Schließlich, im vierten Teil des Aufsatzbandes, betrachten sie Europa als Schauplatz der Geschichte und zugleich als ein Problem der Historiographie. Alle Beiträge verbindet der Bezug auf Gangolf Hübinger und sein Verständnis von Geschichtswissenschaft als intellektuellem Beruf.

Inhaltsübersicht

Friedrich Wilhelm Graf: Einleitung: Problemgeschichte(n) denken. Zu Gangolf Hübingers impliziter Historik

\section{Zur Theorie der Geschichte: Selbstreflexion und Impulse}

Karl Schlögel: Chronotop - Überlegungen zur Räumlichkeit von Geschichte nach dem »spatial turn« - Reinhard Blänkner: Geschichte und Geschehen. Zur Historizität der »Geschichte« als Wissensform - Barbara Picht: Moderne denken. Zeittheorien bei Bauman, Braudel und Koselleck - Walter Erhart: Literaturgeschichte denken - Lutz Raphael: »Gescheiterte Krisen«. Geschichtswissenschaftliche Krisensemantiken in Zeiten postmoderner Risikoerwartung und Fortschrittsskepsis - Dieter Langewiesche: Laien-Historiographie mit hohem Anspruch. Naturwissenschaftler erklären Geschichte: Emil du Bois-Reymond und Justus von Liebig

\section{Geschichtsdenker und Geschichtsintellektuelle}

Wolfgang Hardtwig: „Die Geschichte des Revolutionszeitalters«. Ein neues Hauptwerk von Jacob Burckhardt - Edith Hanke: Max Weber und die historische Empirie - Guenther Roth: Archivrecherchen im Umfeld von Max Weber - Max Spohn: Eine frühe Form der historischen Soziologie: Stefan Czarnowski - Benedikt Stuchtey: Eric Hobsbawm und Victor Kiernan über Revolution und Expansion - Sérgio da Mata: Geschichts-Intellektuelle in der Krise. Das Unbehagen in der heutigen brasilianischen Geschichtswissenschaft

\section{Geschichtsdenken interdisziplinär}

Wolf Feuerhahn: Was ist ein Streitbegriff? Über den »Prozeß der Zivilisation« bei Norbert Elias - Wolfgang Schwentker: „Karisuma« in Japan? Übersetzung, Deutung und Anwendung einer fremdkulturellen Kategorie - Christian Hörnlein: Abgrenzungen und politische Konversionen. Anmerkungen zum Konzept sozialmoralischer Milieus bei M. Rainer Lepsius Beate Henn-Memmesheimer: Geschichte als Wortgeschichte denken. Eine linguistische Perspektive auf Kult - Bożena Chołuj: Vergessen aus Mangel an Beweisen? Die Solidarność-Frauen im toten Winkel von Denkgewohnheit und Methodentradition der polnischen historischen Forschung - Dittmar Dahlmann: Peter Simon Pallas' wissenschaftliches Werk und die Entfaltung der Wissenschaften an der Wende vom 18. zum 19. Jahrhundert - Klaus Weber: Von der Plantage zum »working prison«. Ein kurzer Überblick zur Historiographie der Sklaverei - Hinnerk Bruhns: Über die Ökonomie der Historiker und die Historie der Ökonomen. Streiflichter vom Beginn des 20. Jahrhunderts - Barbara Beßlich: Von der »Alchemie der Zukunft« zum Glauben der Väter. Hermann Bahrs Erlösungshoffnung und Geschichtsdenken zwischen Nationalökonomie und Katholizismus

\section{Europa als Schauplatz und Problem der Historiographie}

Christoph Cornelißen: Transnationale Geschichte als Herausforderung an die Europa-Historiographie - Christof Dipper: Die Vielfalt der Moderne. Darmstadt um 1900 - Roger Chickering: Thomas Mann auf Hamsterfahrt. Selbstisolierung und Deutungsansprüche des Intellektuellen im Krieg 1914-1918 - Friedrich Lenger: Krieg, Nation und Kapitalismus 1914-1918. Werner Sombart, seine Freunde, Kollegen und das Archiv für Sozialwissenschaft und Sozialpolitik - Meike G. Werner: Freideutsche Jugend und Politik. Rudolf Carnaps Politische Rundbriefe 1918 - Nikolai Wehrs: Ernst Troeltschs politische Auslandskontakte nach 1918

Friedrich Wilhelm Graf Geboren 1948; Studium der Ev. Theologie, Philosophie und Geschichte in Wuppertal, Tübingen und München; 1978 Promotion; 1986 Habilitation; Prof. em. für Systematische Theologie und Ethik an der EvangelischTheologischen Fakultät der Ludwigs-Maximilian-Universität München.

Edith Hanke ist Generalredaktorin der Max Weber-Gesamtausgabe, München.

Barbara Picht ist Akademische Mitarbeiterin an der Axel Springer-Stiftungsprofessur für deutsch-jüdische Literatur- und Kulturgeschichte, Exil und Migration an der Europa-Universität Viadrina, Frankfurt (Oder). 
Jetzt bestellen:

https://mohrsiebeck.com/buch/geschichte-intellektuell-9783161541612?no_cache=1

order@mohrsiebeck.com

Telefon: +49 (0)7071-923-17

Telefax: +49 (0)7071-51104

Mohr Siebeck GmbH \& Co. KG

Postfach 2040

D-72010 Tübingen

info@mohrsiebeck.com

Mohr Siebeck

www.mohrsiebeck.com 